\title{
Communication and Mathematic reasoning: Theory of planned behavior and inquiry
}

\author{
Abdul Aziz ${ }^{*}$ @ https://orcid.org/0000-0001-6193-3953 \\ Iswahyudi Joko Suprayitno ${ }^{1}$ () https://orcid.org/0000-0003-0779-7545
}

${ }^{1}$ Muhammadiyah University of Semarang, Indonesia

\begin{abstract}
The purpose of this study is to investigate the aspects of communication and mathematical reasoning. In investigating the aspects of mathematical communication with an inquiry approach, of course there are several things observed related to learning mathematics. The focus of the material aims at observing communication and mathematical reasoning within the framework of inquiry, and the theory of planned behavior (TPB) is geometry and algebra. The research method used a qualitative research by looking at case studies with research subjects consisting of 31 prospective mathematics teachers in Semarang city. From the aspect of communication and mathematical reasoning that exists, it can be seen from the answers of 31 prospective mathematics teachers with an authentic point of view of inquiry and a theory of planned behavior for problem solving. From the observation, several cognitive processes are adapted to the authentic framework of inquiry and the theory of planned behavior for algebra and geometry material. In reasoning, a wedge appears between mathematical reasoning and communication adapted to the framework of inquiry and the theory of planned behavior. The contribution of this study is to determine the communication framework and mathematical reasoning from the theoretical aspects of planned behavior and inquiry. It is important to know aspects of communication and mathematical reasoning from a different perspective.
\end{abstract}

\section{ARTICLE INFO \\ Keywords:}

communication; inquiry; reasoning; theory of planned behavior

Article History:

Received: 29 October 2021

Revised: 21 November 2021

Accepted: 02 December 2021

Published: 30 December 2021

How to Cite in APA Style:

Aziz, A. \& Suprayitno, I. J. (2021). Communication and Mathematic reasoning: Theory of planned behavior and inquiry. Journal of Educational Management and Instruction, $1(2), 83-91$.

\section{Introduction}

Many research on communication and mathematical reasoning have been done. But to observe the framework of communication and mathematical reasoning is still not much done. Given the dynamics of communication and mathematical reasoning is always evolving (Williams et al., 2003). Therefore, there is a need for communication and mathematical reasoning from the theoretical aspects of planned behavior and inquiry. The theory of planned behavior is a theory that can also be implemented in learning (Sanchez and Stewart, 2006). This theory observes student behavior in obtaining learning outcomes. Meanwhile, inquiry is a discovery-based method used for learning activities (Komatsu, 2021). These two things need to be studied to see the communication framework and mathematical reasoning.

In classroom learning activities, it can not be separated from the communication aspect. The interaction between educators and students can be realized properly if the communication that is formed is effective. There are three things that need to be considered in realizing effective communication, namely the learning community, standards of reasoning and knowledge (Kaya \& Aydin, 2016). These three aspects have not been maximized in learning activities in the classroom. Each aspect has a 
contribution in the delivery of mathematical ideas. The ability to convey mathematical ideas or ideas both orally and in writing needs to be considered with the requirements of effective communication and has a positive impact on student understanding. Mathematical communication emphasizes the interaction and exchange of mathematical ideas which is an important part for students in expressing their respective mathematical concepts, understanding and evaluating equations and thoughts of other students (Yang et al., 2016).

Verbal communication formed between students and educators, or students with peers can affect mathematical communication skills (Kosko \& Wilkins, 2010). Learning is not only writing activities but also honing verbal skills that can reduce difficulties in learning. Solutions to difficulties in learning can be found when there is verbal communication between students and educators or students and peers. Educators need to have special methods in strengthening students' verbal communication. Strategies such as providing material for exploring and asking questions related to mathematics must be used to generate verbal participation (Cooke \& Buchholz, 2005). This verbal participation will have an impact on mathematical communication. The activity of delivering ideas orally can be used as a reference in measuring the level of understanding of students.

Mathematical communication that is manifested in verbal or written form indicates the ability to think mathematically (Lim \& Chew, 2007). Students who have the ability to express mathematical ideas orally or in writing can be categorized as having good mathematical thinking skills. There is a very close relationship between mathematical communication and mathematical thinking. Strengthening mathematical communication in mathematics class is an effective teaching method to improve achievement and conceptual understanding (Lomibao, et al, 2016) which leads to mathematical thinking skills. It is often found that students in mathematical communication are still low, indicating that mathematical thinking is also low. In learning, efforts need to be made to maximize mathematical communication skills that are mastered by students. Emphasis on efforts to optimize mathematical communication skills, which so far is still low, can be done by minimizing factors that can hinder students' mathematical communication skills. The low level of mathematical communication skills can be seen from the limited number of students' ideas or ideas expressed in oral or written form.

Mathematical reasoning is also related to aspects of thinking. Reasoning is a form of mathematical skill. Reasoning is different from problem solving. Active reasoning is a form of mathematical thinking that generates mathematical ideas with an inquiry approach. Mathematical reasoning tasks provide opportunities to encourage creative thinking. Mathematical reasoning is carried out in several ways; Explaining their thinking, Using the strategies used to make conclusions, Explaining from one concept to another, Proving right or wrong, Comparing the ideas that arise.

In mathematical reasoning, instructions to get student reasons are important. This can be done while interacting with students or when setting requirements to record their responses to assignments. An assessment of current reasoning can lead them to use supportive and enabling clues to get started, or to use clues that encourage them to explore more deeply and reason more convincingly. Educators may also collect student writing or recorded work. This may include recordings using digital tools that allow students to write, draw and verbally communicate their reasons as some teachers did when piloting these resources. The teacher can then take time to assess the reasoning of all students in the class. It provides teachers with information about students' reasoning abilities and diversity in the classroom which can then be used by teachers to plan lessons to improve student reasoning. This planning may involve selecting a particular reasoning task that provides more opportunities for reasoning or to more consciously use clues to elicit, support and encourage students to reason. 
There needs to be a good learning plan that aims to maximize students' mathematical communication skills (Hartinah et al., 2019) and their reasoning. A clear learning plan will lead to learning difficulties experienced by students related to learning school mathematics material for questions that have high characteristics. Order Thinking Skills, especially those related to optimizing mathematical communication, are still not optimal. One of the plans made is by asking questions that can explore students' mathematical communication. The right questions can be used as a good stimulus to bring up mathematical communication both orally and in writing (Lomibao, et al, 2016).

One of the causes of low mathematical communication is that it is still not optimal to use the right media or learning methods in teaching and learning activities. The use of media or the application of appropriate learning methods will be able to assist students in optimizing mathematical communication (Sinclair \& Heyd-metzuyanim, 2014). There are still not many studies that raise the use of learning media or teaching methods, especially in improving mathematical communication. This ability is one of the important aspects in learning mathematics in the classroom. The use of good learning media or teaching methods packaged in measurable learning designs can improve students' mathematical communication (Sundayana et al., 2017).

In addition to media or teaching, mathematical communication also has different forms depending on the teaching material. There are different forms of mathematical communication in learning geometry and algebra (Pantaleon, et al, 2018). The differences in each material in mathematical communication for geometry, students can visualize in the form of images but cannot describe optimally and for algebra they can describe solutions systematically but the discussion is not too deep and the arguments presented are also still weak. This relates to the attitude of students in working on certain questions. There are differences in attitudes in working on problems related to certain materials, namely geometry and algebra.

This attitude will later be used to explore the abilities possessed in solving the questions given (Sadaf, et al, 2012). There are several factors in inquiry that can influence attitudes in finding solutions to problems. The factors contained in the theory of planned behavior and inquiry are combined into a framework in viewing aspects of mathematical communication. This is important to do considering the contribution of mathematical communication in learning has a big role and there are not many studies that combine the theory of planned behavior with inquiry that is raised in the form of a framework. This framework is useful for looking at aspects of mathematical communication because there are some similarities in characteristics and positive aspects in learning between the theory of planned behavior and inquiry. The application of a good framework of a theory that is built will have a positive impact in overcoming learning problems in the aspect of understanding the material (Rattan, et al, 2012).

The framework of a theory, in this case, is the theory of planned behavior that can be used to measure and predict the actions taken in determining a problem solution (Ajzen et al., 2011). This framework is made based on the knowledge possessed. In addition, this framework aims to examine the in-depth relationship between attitudes and behavior in overcoming social, economic and behavioral difficulties (MacFarlane \& Woolfson, 2013). The positive aspects within a framework that are supported based on a strong theory will bring up a new learning concept and can be implemented in learning. Inquiry theory has a strong foundation in conceptualizing a learning that can produce positive learning outcomes. There have been many studies on the theory of inquiry in strengthening learning in the form of models or methods, but there are still not many that relate to the aspect of the framework.

The inquiry framework that is built must have theoretical and practical implications in learning (Garrison \& Arbaugh, 2007). This is not only used by a group of people but by the application of a framework with a wider range. It can be applied to several aspects of learning even though with different educational backgrounds. But the 
essence of learning itself remains the same, so it can be implemented in learning. The supporting instruments or aspects used in developing a framework, in this case inquiry, must also be strong (Arbaugh et al., 2008) and adaptive considering that the form of learning is growing. Theories built in developing a learning framework must be able to adapt to the times and be able to innovate on new things that can improve the quality of learning.

Many inquiry developments are carried out in accordance with certain learning conditions, be it blended learning, online or direct learning (Swan, et al, 2009). All have the same goal of optimizing a theory or inquiry framework combined with other theories in achieving maximum learning outcomes. Of course, in these combinations, there are some shortcomings that are not suitable if implemented in today's conditions considering the development of learning is getting faster and more advanced and requires special techniques to create an appropriate framework. A good framework will produce an assessment format that can be used to measure learning outcomes (Shea et al., 2010).

The Assessment Format can be used to measure thinking ability. Thinking processes can be observed with the right theoretical framework (Sukoriyanto et al, 2016). The framework can help the learning process to be carried out according to the plans that have been prepared. A good framework will be able to assist students in determining the steps of learning. Systematic steps can be used to help students' reasoning in math classes (Rofiki et al., 2018). It is important to develop a good framework based on proven theories.

In this research study, an inquiry framework will be developed with aspects of the theory of planned behavior. The framework by combining the theory of planned behavior and inquiry will be compiled and studied without losing the uniqueness of each. This framework will observe the process and its results and the extent to which it can have a positive impact on learning. This activity is important to do considering that many currently in learning are still conventional and have not maximized learning plans based on work plans. There are still many learning orientations that are more on the result, not the process. In fact, if we examine further, a good process will produce good outcomes. A good process guides the steps also goes well. Effective steps in generating solutions can be used to determine the level of understanding (Syamsuri et al, 2016).

\section{Method \\ Instrument and data collection}

This research was a type of qualitative research by observing aspects of communication and mathematical reasoning. The research subjects were prospective mathematics teachers in the city of Semarang consisted of 31 people who entered the third semester. This subject was selected because the prospective mathematics teacher was taking school mathematics and calculus courses, so the data obtained related to communication and mathematical reasoning can be used to determine the aspects under study. Previously, the 31 prospective mathematics teachers were given an online inquiry approach in learning geometry and algebra.

Prospective mathematics teachers before being given questions, an inquiry learning approach was previously carried out according to the framework of Figure 1. This framework was applied to the explanation of the material with the Zoom meeting media. Furthermore, to find out how the mathematical communication of prospective teachers in solving problems related to algebra and geometry was needed, items that ask for these aspects were needed:

Problem 1. Known $V_{2}=2 V_{1}$. What is the comparison $r_{2}$ and $r_{1}$

Problem 2. If $\mathrm{f}(\mathrm{x})=4-\mathrm{x}^{2}$

Then the maximum value of $f$ is 4

Problem 3. Prove that for every integer $n$, if $n^{2}$ is odd, then $n$ is odd 


\section{Data analysis}

The results of the teacher candidates' answers will be framed in authentic inquiry which is also a form of the cognitive process experienced. The relationship between cognitive and authentic processes can be seen in Table 1 below:

Table 1. Relationship between Cognitive Process and Inquiry Approach

\section{Cognitive Process \\ Designing a solution}

Determine the steps in finding the answer

Control the answer form

Planning the measurement of answers (logical)

Checking answers

Explain the answer obtained

Finding flaws in answering

Indirect reasoning

Adjustment of how to answer with other methods with almost the same characteristics of the questions

\section{Inquiry Approach}

The subject chooses and finds a solution method from several possible ways of answering

The subject finds the steps to answer the question

Set the answer form to lead to the appropriate solution

Combining several ways of answering or combining several formulas (knowledge) that you have to answer the question Using certain methods (formulas/patterns) to check answers Checking answers repeatedly with different techniques to produce the same answer from the previous technique Comparing the methods used or the results obtained with other and proven methods to correct existing deficiencies Comparing how to answer with other methods whose characteristics are almost the same Checking in adjusting how to answer from several existing methods with the same characteristics of the question A complete argument (way of answering) is formed

As for seeing aspects of mathematical communication can be considered the following indicators:

1. To demonstrate mathematical thinking processes

2. To communicate mathematical thinking both verbally and in writing clearly

3. To evaluate mathematical thinking processes communicated orally or in writing

4. To demonstrate mathematical ideas using mathematical language

These four indicators will be used as indicators and benchmarks to see the mathematical communication of prospective teachers.

\section{Results}

Based on the results of the data obtained from student work, it reveals that several student works describe the framework of communication reasoning and mathematical reasoning from the theoretical aspect of planned behavior. From this, it is observed that the results of some student work are seen to represent the desired data. 

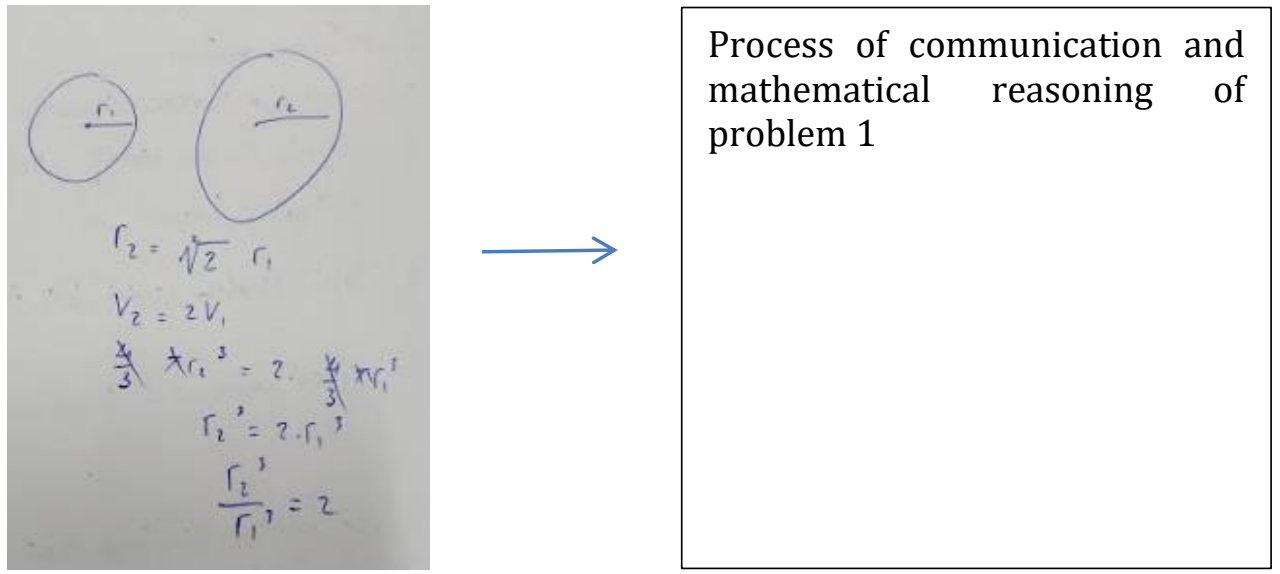

Figure 1. student work results problem

The following is a picture that describes the activities of mathematical reasoning and communication:

1. Analysis

Explore the problem using other proofs

The analysis occurs by comparing the evidence of one with the proof of the second paying attention to:

- what is the same and different

- what remains the same and changes

2. Generating ideas (generalizations) by developing statements. Forming ideas involves identifying common traits in more than one case and conveying conjectures

3. Justification

Deciding with logical arguments it is necessary to check the truth of the allegations and generalizations to show or refute the truth of a claim.

Justification uses logical arguments to convince others of the truth of a claim or to refute a claim.

Logical arguments are made with:

- use ideas that are already understood;

- follow the agreed manufacturing process or steps and

- use familiar and understandable terms, diagrams and symbols.

These activities are also supported by interviews as follows

P1: How did you do the problem?

S1: this question is a matter of comparison

Q1: what do you compare?

$\mathrm{S} 1$ : the $\mathrm{r}$

Q1: What formulas can you compare to work on the problem?

$\mathrm{S} 1$ : formula for the volume of a sphere

The communication framework and mathematical reasoning from the theoretical aspects of planned behavior and inquiries can be seen in the Table 2 .

Table 2. Framework communication and mathematic reasoning

\begin{tabular}{lll}
\hline & Theory of Planned & Inquiry \\
Behavior & \\
\hline Mathematic Communication & - Explaining ideas & - Ability to link certain \\
& - Connecting previous & structures \\
& knowledge & - Ability to analyze and \\
& - Interpret in writing & demonstrate ideas \\
& & visually \\
\hline
\end{tabular}




\begin{tabular}{|c|c|c|}
\hline & $\begin{array}{l}\text { Theory of Planned } \\
\text { Behavior }\end{array}$ & Inquiry \\
\hline Mathematic Reasoning & $\begin{array}{l}\text { - Drawing conclusions } \\
\text { based on previous } \\
\text { concepts } \\
\text { - Connecting between } \\
\text { concepts } \\
\text { - Analyze every step of } \\
\text { the solution }\end{array}$ & $\begin{array}{l}\text { - Designing conjectures } \\
\text { and compiling evidence } \\
\text { - Create relationship } \\
\text { patterns } \\
\text { - Analyzing the theories } \\
\text { that have been mastered }\end{array}$ \\
\hline
\end{tabular}

\section{Discussion}

Students are also required to provide justification and explanation, and why they apply the theory and process. In addition, students are also asked to write down their reflections. It is given to students to internalize what they learn from their class participation, behavior and amount of work done during the lesson and to identify topics they do not understand and find difficult (Herawaty et al., 2019). They are given the opportunity to review their work and assess themselves. The reflection provides more information about their progress and encourages them to take responsibility for their own learning(Santos, 2019). Compared to the findings of working on math problems, the authentic form of inquiry in working on geometry problems is simpler. The authentic process of inquiry that is passed in the form of mathematical communication that refers to cognitive thinking abilities (Siddiky, 2021).

There are several aspects of the communication framework and mathematical reasoning that are almost the same when viewed from the theory of planned behavior. This can be seen in table 1 and several previous studies. There are some slight differences between the theoretical framework of planned behavior and inquiry. This shows how important the aspects of communication and mathematical reasoning are when viewed from the TPB and inquiry framework (Buyung, Sumarli and Rosmaiyadi, 2020). Through this framework, it will be very helpful for teachers in terms of strengthening learning methods by analyzing every indicator that appears in aspects of communication and mathematical reasoning (Berkowitz and Hoppe, 2009).This activity will help students' thinking processes in understanding the material.

\section{Conclusion}

Communication and mathematical reasoning with an inquiry approach in working on algebra problems have a positive impact on prospective teachers. This can be seen from the complexity of the steps in working. On the other hand, the mathematical communication geometry presented is also quite good, although it is not as complex as working on algebra problems. This can happen because algebraic problems provide more explanations than problem solving so that they require broader sentences or answers, unlike the case with geometry, which can be explained enough with pictures for how to answer it and then adjust the correct solution to the problem given. As students develop their capacity to analyze, they become more systematic and pay more attention to problems. The steps in this development are summarized (general property, pattern or relationship), remembering and repeating, trying to organize; sort, classify, notice, explain; search, predict, explore relationships, notification relationships. Contributions in this research to help teachers understand the indicators of communication and mathematical reasoning. This is very important in learning mathematics. The limitation in this research is that the TPB and inquiry frameworks have not been separated, in other words, they are still combined. Therefore, for further research, a separate framework of communication and mathematical reasoning can be used in terms of the TPB and inquiry aspects. 


\section{References}

Arbaugh, J. B. et al. (2008). Internet and Higher Education Developing a community of inquiry instrument: Testing a measure of the Community of Inquiry framework using a multi-institutional sample. The Internet and Higher Education. Elsevier Inc., 11(3-4),133-136. doi: 10.1016/j.iheduc.2008.06.003.

Berkowitz, M. W. and Hoppe, M. A. (2009). Character education and gifted children. High Ability Studies. 20(2), 131-142. doi: 10.1080/13598130903358493.

Buyung, B., Sumarli, S. and Rosmaiyadi, R. (2020). Development of problem based learning based on ethnomatematics to support students mathematics literacy ability and self-confidence. AIP Conference Proceedings, 2268. doi: 10.1063/5.0017833.

Cooke, B. D. and Buchholz, D. (2005). Mathematical communication in the classroom: A teacher makes a difference. Early Childhood Education Journal, 32(6), 365-369. doi: 10.1007/s10643-005-0007-5.

Hartinah, S. et al. (2019). Probing-prompting based on ethnomathematics learning model: The effect on mathematical communication skills. Journal for the Education of Gifted Young Scientists, 7(4), 1-16. doi: 10.17478/jegys.574275.

Herawaty, D. et al. (2019). The Improvement of the Understanding of Mathematical Concepts through the Implementation of Realistic Mathematics Learning and Ethnomathematics. 295(ICETeP 2018), 21-25. doi: 10.2991/icetep-18.2019.6.

Kaya, D. and Aydin, H. (2016). Elementary mathematics teachers' perceptions and lived experiences on mathematical communication. Eurasia Journal of Mathematics, Science and Technology Education, 12(6), 1619-1629. doi: 10.12973/eurasia.2014.1203a.

Komatsu, K. (2021). Generating mathematical knowledge in the classroom through proof, refutation, and abductive reasoning. Educational Studies in Mathematics. doi: 10.1007/s10649-021-10086-5.

Kosko, K. W. and Wilkins, J. L. M. (2010). Mathematical communication and its relation to the frequency of manipulative use. International Electronic Journal of Mathematics Education, 5(2), 79-90.

Lim, C. S. and Chew, C. M. (2007). Improving mathematical communication ability and self regulation learning of yunior high students by using reciprocal teaching. Journal on Mathematics Education, 4(1), 59-74.

Lomibao, L. S., Luna, C. A. and Namoco, R. A. (2016). The Influence of Mathematical Communication on Students' Mathematics Performance and Anxiety. American Journal of Educational Research, 4(5), 378-382. doi: 10.12691/education-4-5-3.

MacFarlane, K. and Woolfson, L. M. (2013). Teacher attitudes and behavior toward the inclusion of children with social, emotional and behavioral difficulties in mainstream schools: An application of the theory of planned behavior. Teaching and Teacher Education. Elsevier Ltd, 29(1), 46-52. doi: 10.1016/j.tate.2012.08.006.

Pantaleon, K. V., Juniati, D. and Lukito, A. (2018). The oral mathematical communication profile of prospective mathematics teacher in mathematics proving. Journal of Physics: Conference Series, 1108(1). doi: 10.1088/1742-6596/1108/1/012008.

Rattan, A., Good, C. and Dweck, C. S. (2012). It's ok - Not everyone can be good at math": Instructors with an entity theory comfort (and demotivate) students. Journal of Experimental Social Psychology. Elsevier Inc., 48(3), 731-737. doi: 10.1016/j.jesp.2011.12.012.

Sadaf, A., Newby, T. J. and Ertmer, P. A. (2012). Exploring factors that predict preservice teachers' intentions to use web 2.0 technologies using decomposed theory of planned behavior. Journal of Research on Technology in Education, 45(2), 171-196. doi: 10.1080/15391523.2012.10782602.

Sanchez, T. R. and Stewart, V. (2006). The Remarkable Abigail: Story-Telling for 
Character Education. The High School Journal, 89(4), 14-21. doi: 10.1353/hsj.2006.0008.

Santos, M. (2019). Units of Measurement in Social Practices: An Ethnomathematic Study. American International Journal of Contemporary Research, 9(2), 32-39. doi: 10.30845/aijcr.v9n2p4.

Siddiky, R. (2021). Association between Students Inattentiveness to Study and their Psychological Conditions during the COVID-19 Pandemic. Asian Journal of University Education, 17 (2), 27-38.

Sinclair, N. and Heyd-metzuyanim, E. (2014). Learning Number with TouchCounts : The Role of Emotions and the Body in Mathematical Communication. Journal: Technology, Knowledge, and Learning, 1(2). doi: 10.1007/s10758-014-9212-x.

Sukoriyanto, J. et al. (2016). Students thinking process in solving combination problems considered from assimilation and accommodation framework. Educational Research and Reviews, 11(16), 1494-1499. doi: 10.5897/err2016.2811.

Sundayana, R. et al. (2017). Using ASSURE learning design to develop students' mathematical communication ability. World Transactions on Engineering and Technology Education, 15(3), 245-249.

Swan, K., Garrison, D. R. and Richardson, J. C. (2009). A constructivist approach to online learning: The community of inquiry framework. Information Technology and Constructivism in Higher Education: Progressive Learning Frameworks, 43-57. doi: 10.4018/978-1-60566-654-9.ch004.

Syamsuri et al. (2016). Characterization of students formal-proof construction in mathematics learning. Communications in Science and Technology, 1(2), 42-50. doi: 10.21924/cst.1.2.2016.2.

Williams, D. D. et al. (2003). Character education in a public high school: A multi-year inquiry into unified studies. Journal of Moral Education, 32(1), 3-33. doi: 10.1080/0305724022000073310.

Yang, E. F. Y. et al. (2016). Improving Pupils ' Mathematical Communication Abilities Through Computer-Supported Reciprocal Peer Tutoring Linked references are available on JSTOR for this article : Improving Pupils ' Mathematical. International Forum of Educational Technology \& Society, 19(3), 157-169. 